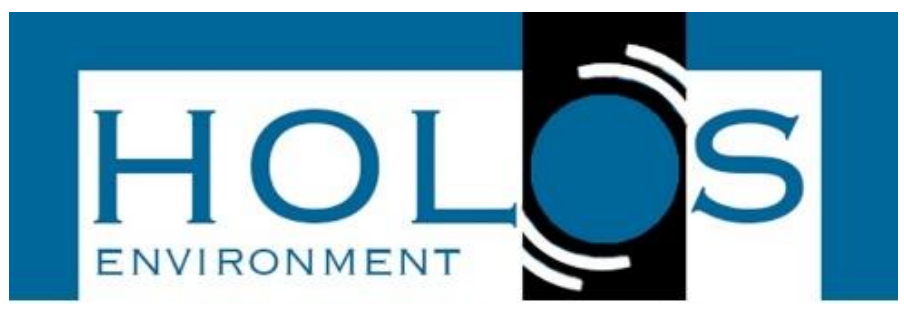

\title{
A IMPORTÂNCIA DO LICENCIAMENTO AMBIENTAL NA PARAÍBA PARA EXTRAÇÃO DE AREIA EM LEITO DE RIO
}

\section{THE IMPORTATION OF ENVIRONMENTAL LICENSING IN PARAÍBA FOR RIVERBED SAND EXTRACTION}

\author{
Gerson Ferreira da Silva ${ }^{1}$
}

Artigo recebido em: 14/11/2019 e aceito para publicação em: 08/01/2020.

DOI: http://dx.doi.org/10.14295/holos.v20i1.12361

\begin{abstract}
Resumo: Geologicamente, o termo areia é definido como um material detrítico com variação de tamanho de partículas definidas, composta principalmente por partículas de quartzo, mas outros minerais também podem ser encontrados, tais como: feldspato, mica e turmalina. É notória a importância da atividade de extração de areia para o desenvolvimento socioeconômico do estado da Paraíba, porém, deve-se estar atento ao impacto ambiental que essa atividade proporciona, como: processos erosivos, e alterações na geomorfologia fluvial dos cursos do rio. Neste contexto, a presente pesquisa tem como principal objetivo apresentar a importância de desenvolver a exploração desse bem mineral de forma adequada. Sendo assim, são apresentados os impactos ambientais positivos e negativos, e principalmente os procedimentos para realizar o Licenciamento Ambiental de uma área no município de São João do Cariri-PB, já que é comum as empresas trabalharem clandestinamente.
\end{abstract}

Palavras-chave: Licença Ambiental. Areia. Rio. Construção Civil.

Abstract: Geologically, the term sand is defined as a detrital material with varying size of use, composed mainly of quartz particles, but other minerals can also be found, such as feldspar, mica and tourmaline. With significant growth in construction in recent years, there has been a demand for sand exploration, which is one of the main natural resources to supply this market. Sand extraction is important for the socioeconomic development of the state of Paraíba, however, be aware of the environmental impact that this activity provides, such as: erosive processes and changes in the river stream geomorphology. In this context, this research aims to present the importance of developing the exploration of this mineral properly. Thus, the positive and negative environmental impacts are presented, and especially the procedures to perform the Environmental Licensing of an area in the municipality of São João do Cariri-PB, as it is common as companies that work underground.

Keywords: Environmental license. Sand. River. Construction.

\section{INTRODUÇÃO}

Nas últimas décadas, a questão ambiental vem ganhando espaço nas preocupações da sociedade e dos segmentos mais esclarecidos. Sendo assim, o crescimento económico vem sendo repensado, com a busca de alternativas, como o desenvolvimento sustentável,

\footnotetext{
1 Doutorando em Engenharia de Minas. Universidade Federal do Rio Grande do Sul (UFRGS), Porto Alegre, RS. E-mail: (gmineracao@hotmail.com)
} 
conciliando a preservação do meio ambiente, o desenvolvimento e a melhoria da qualidade de vida.

O Brasil é um dos poucos países, senão o único, a ter um processo de licenciamento ambiental dividido em três etapas (Licença Prévia, Licença de Instalação e Licença de Operação), com procedimentos separados para concessão das licenças em diferentes estágios. Contudo, por ser um processo trifásico, o licenciamento ambiental brasileiro tem duração excessiva até a concessão da licença de operação.

A Deliberação 3577/2014, do Conselho de Proteção Ambiental (COPAM), definiu normas e procedimentos para licença ambiental da extração de mineral de agregado para leito de rios e riachos no Estado da Paraíba. Baseado nas normas, a extração em curso de água perene natural (rio que sempre tem água fluindo em seu leito) para o comércio poderá ser realizada de maneira mecanizada. O mesmo acontece com a extração comercial em curso de água intermitente (rio que seca em determinada época do ano).

Desde a sua implantação, o procedimento de licenciamento ambiental vem instituindo novos instrumentos e estudos ambientais que dão suporte à análise das licenças ambientais de empreendimentos que pretendem se instalarem no território paraibano.

Sabe-se que a atividade de extração de areia e cascalho para uso na construção civil está associada á frequência da ocorrência do bem, e ao contexto de representatividade daquele bem para o mercado e sociedade. A atividade mineraria apresenta grande ocorrência de instalações clandestinas e de fácil escoamento da produção em função da demanda pelo mercado consumidor, esta situação tem corno consequência um elevado número de intervenções por parte da fiscalização ambiental (BANCO DO NORDESTE, $p$ 201, 1999).

De acordo com a Lei Federal 6.938/81, o Licenciamento Ambiental tornou-se obrigatório em todo o território nacional e as atividades efetiva ou potencialmente poluidoras não podem funcionar sem o devido licenciamento.

Sendo assim, esse trabalho apresenta a importância, e os procedimentos de regularização junto aos órgãos ambientais para as pessoas físicas e jurídicas, que exploram areia na região da Paraíba, e também mostrar que estão sujeitas às sanções previstas em lei, incluindo as punições relacionadas na Lei de Crimes Ambientais, instituídas em 1998: advertências, multas, embargos, paralisação temporária ou definitiva das atividades.

\section{REVISÃO BIBLIOGRÁFICA}

\subsection{Mineração e Impacto Ambiental}

A grande variedade de problemas ambientais das minerações pode ser categorizada em um pequeno número de variáveis, alguns tipos vão depender do grau de severidade da ocorrência; desta maneira DOWN, STOCKS (1978), dividem em, conforme Quadro 1. 
Quadro 1 - Categorias de problemas ambientais provocados pela mineração

- Risco direto para a segurança do homem: os empreendimentos mineiros apresentam um grande potencial de perigos e de riscos para a segurança dos trabalhadores.

- Risco indireto para o bem estar do homem: São termos de longo prazo e se relacionam com a exposição á poluição, ao ruído, que se transformam em problemas para a saúde pública.

- Perigo para a propriedade, a agricultura e a pecuária: São impactos que se refletem na comunidade do entorno da área lavrada, afetando a qualidade da produção.

- Desconforto, incómodos: alteração na saúde ou segurança do homem.

Fonte: DOWN; STOCKS (1978)

Os riscos diretos para a segurança do homem situam-se na operação, no transporte, e na estocagem; por outro lado, a segurança pública, como um outro aspecto dos riscos, tem corno principais características: falhas em reservatórios, vazamentos em barragens de resíduos, lagoas de decantação, escorregamentos nas paredes das minas com reflexos no entorno da área minerada: principalmente em lugares abandonados, vazamentos de efluentes tóxicos; uso de explosivos e finalmente, o transporte de minério.

Riscos indiretos para o bem estar do homem são medidos normalmente adotadas para eliminar ou minimizar as feições geradas pela mineração e que possuam um perigo indireto ao homem são, poluição do ar e da água por metais e substâncias tóxicas, barulho, ruído e poeiras, que causam problemas para a saúde pública.

Perigo a propriedade, agricultura e pecuária são problemas que refletem desde a perda de qualidade de vida, até a queda da produtividade.

Desconforto e incómodo são critérios difíceis de obter quantificação e/ou normas de aceitação geral, podendo classificar-se em intrusão visual, barulho e vibrações, baixos níveis de poluição do ar e da água e, finalmente abandono de áreas a sorte do tempo, limitando o seu potencial de uso.

\subsection{Os impactos ambientais da extração da areia}

De acordo com a norma da Associação Brasileira de Normas Técnicas - ABNT de outubro de 1988, que procura caracterizar as cargas poluidoras na mineração, a retirada da natureza causa várias alterações, em suas diversas fases, relatado também por SILVA (1996), entre outros citados.

Estas fases são a pesquisa mineral, a lavra (com implantação, operações e construções, além da operação de suspensão das atividades), beneficiamento (com implantação e operação) e manuseio da areia no depósito, contando ainda com as atividades de apoio.

As extrações analisadas são realizadas em leitos de cursos d'água, apresentando, pelos relatos de Bruschi; Peixoto (1997), alterações na paisagem, supressão da vegetação, modificação na estrutura do solo (compactação, exposição solar e mudanças na estrutura microbiológica), interferência sobre a fauna, conflitos de uso do solo e de uso dos recursos naturais, alterações nas calhas dos cursos d’água, alteração do nível do lençol freático, 
trepidação, poluição sonora; poluição atmosférica, contaminação por óleos e graxas, instabilidade das margens e taludes, turbidez das águas, efluentes líquidos, resíduos sólidos e alterações no tráfego local e regional.

Segundo MELO (2010), qualquer umas das formas de ocorrência e de extração de areia pode acarretar em impactos ambientais. Estes podem ser positivos, proporcionando benefícios sociais, ou negativos, proporcionando diferentes prejuízos.

Os impactos ambientais decorrentes da implantação dos projetos de extração de areia em leito de rio estão listados a seguir de acordo com a natureza do impacto, positivo ou negativo.

\subsubsection{Impactos positivos}

1. Geração de empregos diretos, bem como de empregos indiretos decorrentes daqueles postos de trabalho que dependem da areia, como: caminhoneiros que transportam a areia, empregados da construção civil como um todo, pessoas ligadas ao comércio de materiais de construção em geral, além de profissionais liberais como geólogos, advogados e contadores.

2. Dinamização do setor comercial, devido à aquisição de fatores de produção e à geração de empregos, proporcionando aquecimento da economia local.

3. Contribuição para o desenvolvimento regional com a implantação da rede viária.

4. Aumento da receita dos governos estaduais c, principalmente municipais, em virtude da obtenção por partes deles, da Compensação Financeira pela Exploração de Recursos Minerais (CFEM).

\subsubsection{Impactos negativos}

1. Depreciação da qualidade do ar, devido ao lançamento de gases provenientes dos motores e de partículas sólidas, em virtude da utilização de maquinários em diferentes operações.

2. Incidência de processos erosivos no solo, em virtude da interferência advinda da abertura da rede viária e da remoção da vegetação, com a consequente depreciação da sua qualidade.

3. Diminuição da infiltração de água no solo, devido compactação ocasionada pelo uso de máquinas pesadas e a impermeabilização promovida pela instalação da infraestrutura do empreendimento.

4. Depreciação da qualidade do solo, decorrente da diminuição da sua fertilidade, plasticidade e aeração, por causa da compactação pelo uso de maquinários pesados.

5. Aumento da concentração de partículas em suspensão (turbidez) no curso d'água, em virtude do surgimento de fenômenos erosivos, decorrentes da exposição do solo ás intempéries.

6. Regularização da vazão dos cursos d'água, devido à supressão da cobertura vegetal e da compactação do solo. 
7. Danos à microbiota do solo, ocasionados pelos trabalhos de remoção da vegetação e abertura da rede viária e pela interferência direta nesta, decorrente da compactação dos solos.

No estado da Paraíba, com 380 quilômetros de comprimento e de extrema importância para o estado devido à sua extensão e relevância econômica, o Rio Paraíba está correndo riscos com o aumento na "indústria" de extração de areia e cascalho do seu leito para a utilização, principalmente, na construção civil. Em nosso estado boa parte das empresas que exploram a extração de areia e cascalho atuam de forma clandestina (Figura 2).

Figura 2 - (a) Extração no leito do Rio Paraíba, (b) Extração de areia na região do cariri-PB

a)

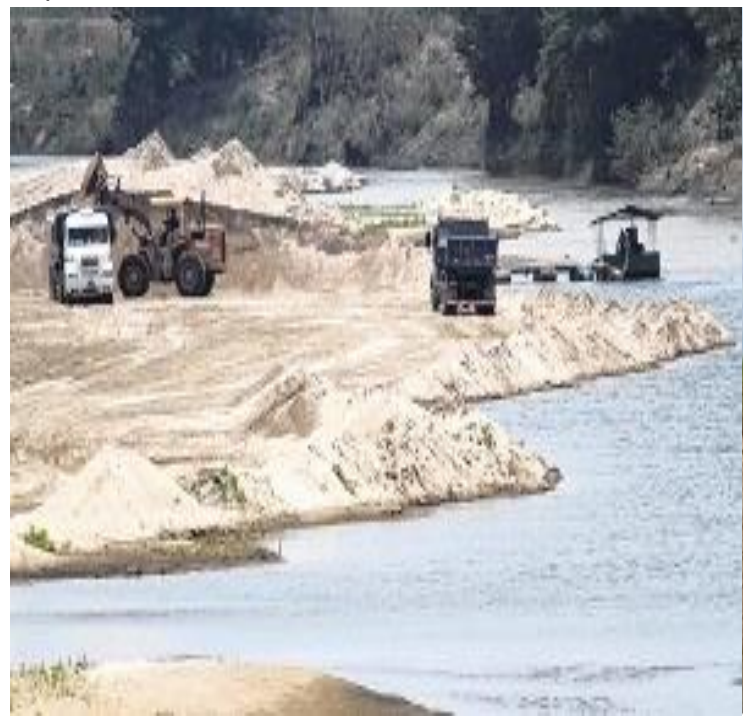

Fonte: Autoria (2019) b)

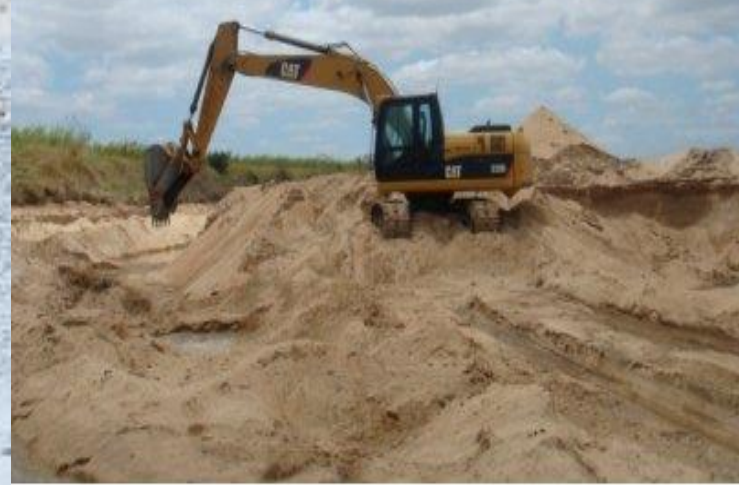

\section{MATERIAL E MÉTODOS}

O presente trabalho foi desenvolvido de acordo com os procedimentos requeridos para realização de uma pesquisa científica. Inicialmente para realizar as atividades visando a obtenção do Licenciamento Ambiental na área selecionada, teve-se a necessidade de fazer um levantamento de informações junto ao Conselho Nacional do Meio Ambiente (CONAMA), no Instituto Brasileiro do Meio Ambiente e dos Recursos Naturais Renováveis (IBAMA), e uma consulta documental no orgão ambiental da Paraíba, SUDEMA Superentendência de Administração do Meio Ambiente.

Em seguida para conhecimento da sociedade, e apresentação da importância do licenciamento ambiental para exloração de areia realizou-se uma ampla revisão bibliografica relacionada ao tema, por meio de dissertaçãoes e teses. Durante a visita a região de estudo (Figura 1), realizou-se um reconhecimento da área pretendida, por meio de caminhadas ao longo do leito do rio, coleta de coordenadas geográficas, e registro do comportamento do rio e sua vegetação, in loco e a partir de fotografias aéreas. Depois de coletado os dados de campo, que são imprescindíveis para os trabalhos, e definido os limites da área a ser licenciada, procedeu-se com o refinamento dessas informações. 
Por fim, realiza-se na prática, todos os procedimentos necessários para legalização de uma atividade minerária de extração de areia, no municipio de São João do Cariri, no estado da Paraíba.

Figura 1 - Mapa de localização da área estudada

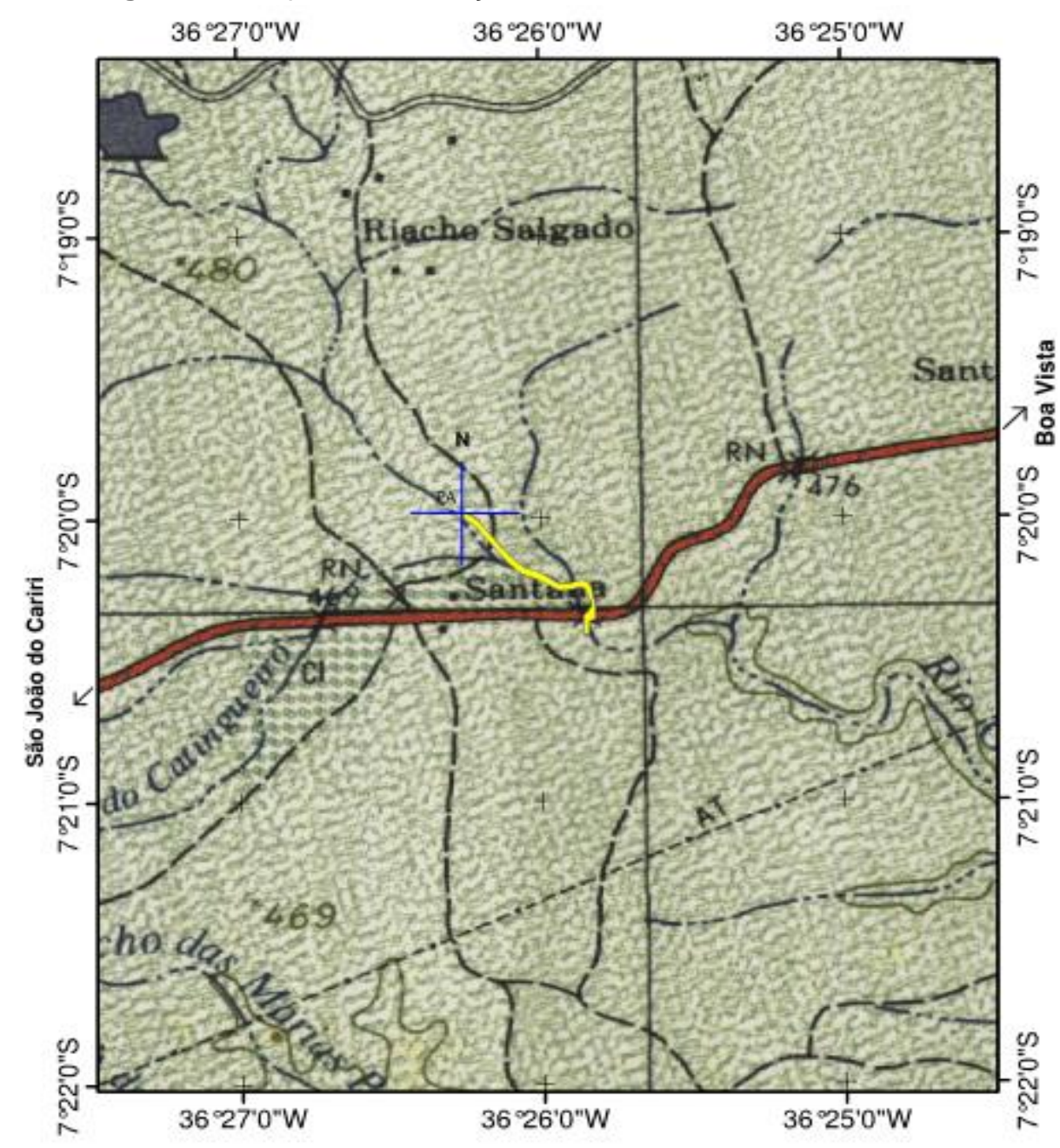

Fonte: Autoria (2019)

\section{RESULTADOS E DISCUSSÃO}

O registro de licenciamento para da extração de areia é realizado através de requerimento na ANM (Agência Nacional de Mineração), disciplinado pela Lei Federal $n^{\circ} 6.567$, de 24 de setembro de 1978, que dispõe sobre o regime especial para exploração e o aproveitamento de substancias mineral. Esta licença deve ser expedida pela autoridade administrativa local, com validade somente após o seu registro no ANM e publicado no Diário Oficial da União (DOU). O aproveitamento mineral é facultado exclusivamente ao proprietário do solo ou a quem dele detiver autorização expressa. Além do regime de licenciamento na Agência Nacional de Mineração (ANM), a extração também deve obter sua licença ambiental, para regularizar o empreendimento minerário.

O licenciamento ambiental é um procedimento no qual o poder público, representado por órgãos ambientais, autoriza e acompanha a implantação e a operação de atividades, 
que utilizam recursos naturais ou que sejam consideradas efetiva ou potencialmente poluidoras. No caso dessa pesquisa, trata-se de uma área voltada à extração de areia em leito de rio, e esta atividade é considerada como poluidora. Desta forma, tem-se a obrigação do empreendor, prevista em lei, buscar o licenciamento ambiental junto ao órgão competente.

Vale salientar que todo empreendimento listado na Resolução CONAMA 237 de 1997 é obrigado a ter licença ambiental. O quadro 2 apresenta algumas atividades que estão sujeitas ao licenciamento ambiental, e neste caso, segue-se com os procedimentos legais para a regularização.

Quadro 2 - Categorias de problemas ambientais provocados pela mineração

\begin{tabular}{|c|c|}
\hline Extração e tratamento de minerais & $\begin{array}{c}\text { Indústria de produtos minerais não } \\
\text { metálicos }\end{array}$ \\
\hline Pesquisa mineral com guia de utilização. & $\begin{array}{c}\text { Beneficiamento de minerais não } \\
\text { metálicos, não associados à } \\
\text { extração }\end{array}$ \\
\hline $\begin{array}{c}\text { Lavra a céu aberto, inclusive de aluvião, } \\
\text { com ou sem beneficiamento. }\end{array}$ & $\begin{array}{c}\text { Fabricação e elaboração de produtos } \\
\text { minerais não metálicos tais como: } \\
\text { produção de material cerâmico, cimento, } \\
\text { gesso, amianto e vidro, entre outros. }\end{array}$ \\
\hline
\end{tabular}

Fonte: Adaptado Andrade (1997)

A licença ambiental, no qual iremos requerer junto a SUDEMA, órgão estadual da Paraíba, corresponde a um documento, com prazo de validade definido, em que o órgão ambiental estabelece regras, condições, restrições e medidas de controle ambiental a serem seguidas pelo empreendedor minerário. Entre as principais características avaliadas no processo podemos ressaltar: o potencial de geração de líquidos poluentes (despejos e efluentes), resíduos sólidos, emissões atmosféricas, ruídos e o potencial de riscos de explosões e de incêndios. Ao receber a Licença Ambiental, o empreendedor assume os compromissos para a manutenção da qualidade ambiental do local em que se instala.

Esse processo de registro de licenciamento é constituído de três tipos de licenças, e são denominadas como: Licença Prévia (LP), Licença de Instalação (LI) Licença de Operação (LO), cada uma é exigida em uma etapa especifica. A Figura 2 representa as etapas necessárias para dá entrada ao pedido das referidas licenças.

No caso da pesquisa em questão, trata-se de um empreendimento novo. Assim, seguimos os procedimentos para obtenção das LP, LI e LO em uma área localizada no município de São João do Cariri-PB.

Inicialmente observam-se os limites da área em estudo para saber se ultrapassa o estado da Paraíba, e se devem ser licenciado pelo IBAMA ou o órgão da Paraíba. Em nossa situação, o empreendimento cujos potenciais impactos ambientais estão restrito ao nosso estado, o processo para o Licenciamento é dirigido a SUDEMA. 
Figura 2 - Etapas do processo de licenciamento ambiental

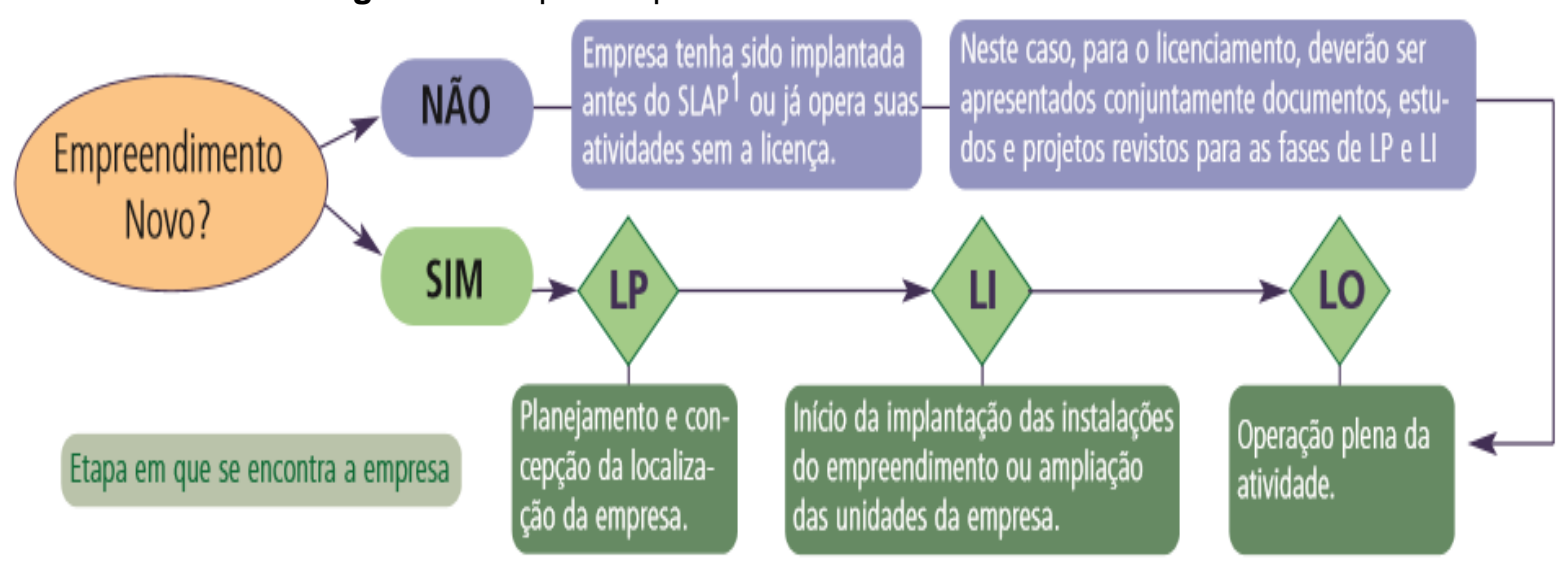

Fonte: Feitosa; Fagundes (2004)

Uma vez determinado o órgão licenciador, é necessária a ida a esse estabelecimento ou visitar o site da SUDEMA, e solicitar os formulários de requerimento compatível com a atividade a ser pretendida, em nosso caso, extração de areia em leito de rio. De acordo com o tamanho da empresa, a tipologia, o grau de risco e a fase de licenciamento poderá haver diferenciação em relação aos documentos e procedimentos exigidos. No Quadro 3 segue os principais documentos exigidos no licenciamento ambiental na Paraíba.

Quadro 3 - Principais Documentos Exigidos na Paraíba para o Licenciamento Ambiental

\begin{tabular}{|l|}
\hline \multicolumn{1}{|c|}{ Documentos Exigidos pela SUDEMA } \\
\hline Formulário de requerimento da licença pretendida (LP, LI e/ou LO); \\
\hline Cadastro de atividades do extrativismo mineral; \\
\hline Cópia da comprovação de titularidade da área do empreendimento; \\
\hline Certidão de uso e ocupação do solo expedida pela prefeitura municipal; \\
\hline Planta de locação e situação da área de extração georreferenciada; \\
\hline Mapa de acesso ao local, com referências; \\
\hline Comprovante de inscrição no cadastro técnico federal do IBAMA; \\
\hline Apresentação do ElA/RIMA ou do RCA, o que couber; \\
\hline Anotação de responsabilidade técnica (ART) de todos os profissionais envolvidos; \\
\hline Cadastro ambiental rural da propriedade (CAR); \\
\hline Licença municipal para extração mineral; \\
\hline Apresentação do PCA/PRAD; \\
\hline Registro de licença na ANM (Agência Nacional de Mineração). \\
\hline Fonte: SUDEMA-PB
\end{tabular}

Em seguida é feito o preenchimento do requerimento da licença (LP), e do cadastro de atividade do extrativismo mineral. Esse documento é descrito com informações e atividades da pessoa física e/ou jurídica contendo endereço, produto fabricado, fontes de abastecimento de água, efluentes gerados, destino de resíduos e produtos estocados. Outros documentos tais como o levantamento de plantas e a descrição dos processos industriais deverão ser anexados ao cadastro de atividade industrial. 
Depois de preenchido o formulário do requerimento, o cadastro industrial e anexados todos os documentos exigidos na Tabela 2, encaminha-se a SUDEMA para a abertura do processo de licenciamento do respectivo empreendimento. Lembrando que todos os documentos serão conferidos e se estiverem corretos será iniciado o processo de licenciamento.

A abertura do processo deverá ser publicada em jornal de circulação e no Diário Oficial do Estado da Paraíba pela empresa. Depois de realizado a publicação, preparar um oficio e protocolar junto com as publicações na SUDEMA. Na Figura 3 tem-se o resumo dos procedimentos, apresentados até o presente momento.

Figura 3 - Resumo das etapas empregadas no processo de licenciamento ambiental

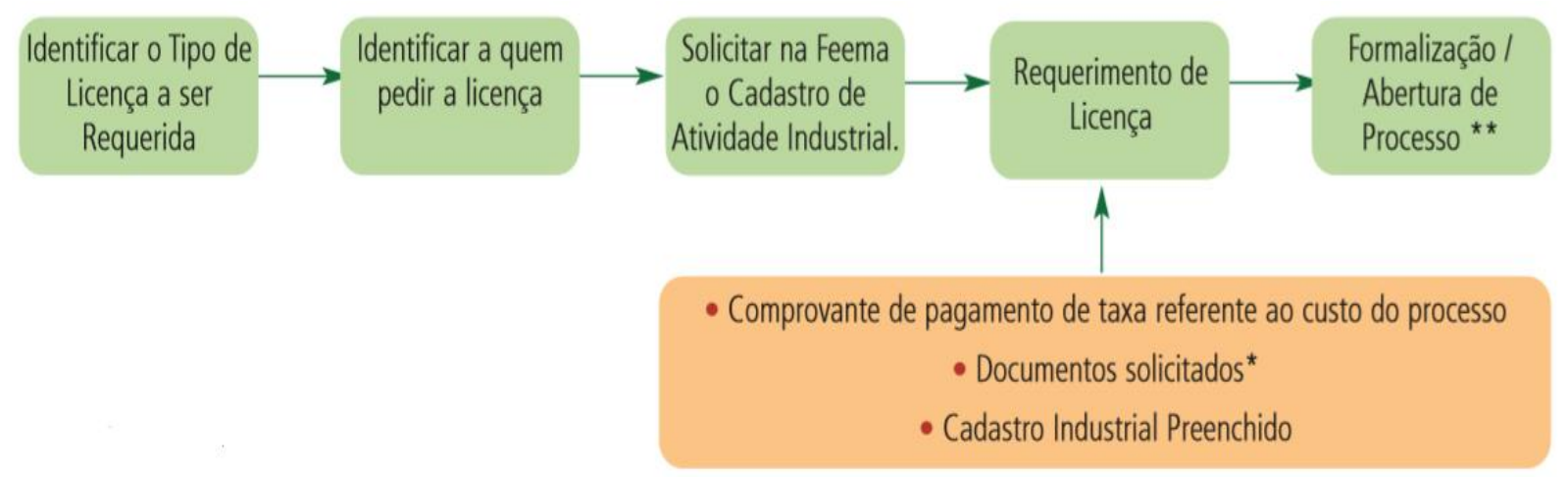

Fonte: Feitosa; Fagundes (2004)

Depois do requerimento devidamente formalizado, o processo segue as etapas de tramitação interna da SUDEMA. Após abertura do processo de requerimento de licença, a pessoa física e/ou jurídica aguarda a definição do respectivo órgão estadual. Nesta fase, os técnicos da SUDEMA analisam os documentos, os projetos e/ou estudos ambientais apresentados pelo empreendedor.

Em um determinado período do processo de licenciamento a empresa receberá a visita de técnicos da SUDEMA para a verificação das condições do empreendimento. Esta vistoria avalia $o$ atendimento às exigências realizadas pelo órgão ambiental e acompanha a execução das medidas de controle propostas pelas empresas em seus planos de ação.

Em qualquer etapa do processo, outras exigências podem ser definidas. A SUDEMA, com base nos resultados destes estudos, decide os itens ou parâmetros que devem ser ajustados, e se a implantação de métodos mais eficazes de controle ambiental é necessária.

Depois da etapa da visita técnica, tem-se a emissão do parecer técnico deferindo ou não a licença requerida. Após o cumprimento de todas as exigências determinadas, a SUDEMA emite um parecer técnico referente aos dados levantados durante 0 licenciamento. Esse parecer é encaminhado ao setor específico do órgão para aprovação ou não da licença Ambiental.

A licença sendo deferida é comunicado aos responsáveis da empresa, e serão convocados a comparecer ao órgão a fim de formalizar o processo. Em seguida, a empresa deve publicar uma nota sobre o recebimento da licença no Diário Oficial do Estado e em um periódico regional (ou local) de grande circulação. 


\section{CONCLUSÕES}

O desenvolvimento dessa pesquisa permitiu realizar um levantamento dos possíveis danos ambientais causados, e de identificar os impactos positivos com a atividade de extração de areia, como a geração de emprego e renda. Também foi possível descrever os principais procedimentos que devem ser seguidos para a legalização da área junto ao órgão estadual ambiental.

O processo de regularização do Licenciamento Ambiental para extração de areia em leito de rio é uma obrigação legal do empreendedor minerário, e é formado por inúmeras etapas e envolve algumas exigências. Desde o início é importante à conscientização da pessoa física e/ou jurídica realizar os trabalhos em parceria com os órgãos ambientais, procurando de maneira clara as soluções para o desenvolvimento de suas atividades de extração preservando o meio ambiente.

Esse processo é muito importante na geração de renda local, e com a regularização do empreendimento, assegura-se ao poder público, a Compensação Financeira de Recursos Minerais - CFEM.

\section{REFERÊNCIAS}

ANDRADE, F. A. V. Resolução CONAMA 237, de 19/12/1997: um ato normativo inválido pela eiva da inconstitucionalidade e da ilegalidade. Revista de Direito Ambiental, n. 13. São Paulo, 1999.

BRUSCHI, D. M.; PEIXOTO, M. C. D. Extração de areia, cascalho e argila , técnicas e controle ambiental. Belo Horizonte: Fundação Estadual de Meio Ambiente. In: Manual de Saneamento e Proteção Ambiental para os Municípios, 1997.

BRASIL . Lei n 6.938, de 17 de Janeiro de 1981. Política Nacional do Meio Ambiente. Brasília. Regulamentada pelo decreto $n^{\circ}$ 99.274, de 66.1990. Diário oficial da União Publicada, Brasília, DF de 2.981 - Efeitos a partir de 7 junho 1990. 1981.

COPAM. Deliberação Normativa COPAM n 3577 de 16/09/2014.

DOWN, C.G.; STOCKS, J. Environmental impact of mining. reprinted, London: Aplied Science Published, 1978.

FEITOSA, I.R; LIMA L.S.; FAGUNDES, R.L. 2004. Manual de licenciamento ambiental: guia de procedimento passo a passo. Rio de Janeiro: GMA, 2004.

MELO, T. F. S. Diagnóstico ambiental em área de exploração mineral: o porto de areia estrela, em Ponta Grossa - PR. Dissertação (Mestrado) - Curso de Programa de Pósograduação em Geografia, Universidade Estadual de Ponta Grossa, PR, 2010.

SILVA, H. V. Alterações da qualidade das águas superficiais pela exploração de areia no município de Itaquaquecetuba - SP. Boletim de Geografia - UEM, n. 01, Maringá, 1996.

RELAÇÃO DE DOCUMENTOS PARA O LICENCIAMENTO AMBIENTAL. Disponível em: www.sudema.pb.gov.br/. Acesso em: 25 out. 2019. 